\title{
Lauren: Response to Greg
}

In content and form, your more foundational piece - not mutually exclusive with "forward-looking" - complements my more postfoundational one; as I say in my mine, it is important to see our pieces as mutually existing in a "both/and" way. We used some of the same authors, but in different ways. Subsequently, we have pulled out intersecting but also diverse themes from this strong collection of articles, and yours has allowed me another round of questioning and reflection:

In that moment with your students, it would be interesting to introduce the work of feminist/postcolonial/Southern philosophies of science as ontological and epistemological interventions. Related to this, how do you deconstruct the notion of "experimentation," formal or otherwise, as a concept that has been historically and contemporarily oppressive?

I also am reminded of Holliday (2013, p. 541)'s important discussions of specifically positivism in the West (and elsewhere) as a problem:

[Qureshi's (2010) 'eloquent' description of 'how things really are' in her research context of Pakistan] is also strikingly resonant with how things are in Britain and perhaps, indeed, everywhere in the West, where there are also collectivities. It is not, therefore, a matter of Western cultures of individualism that cannot tolerate non-Western collectivities. It is, instead, the positivism that Qureshi has encountered that cannot tolerate cultural complexities.

I see the possibilities here to apply to the field of CIE Rohrer (2018)'s insightful pedagogical framework, "It's in the Room," whose origins Rohrer describes:

Students over the years have taught me the power of recognizing that whatever the social justice topic is that we are studying (gender oppression, ableism, racism, colonialism, heterosexism, classism, etc.), it is almost always in the room in some form or another. Further, even if it is somehow not recognized/recognizable in the lives of those present, we should act as if it is. (p. 577) 
The "room" of everything and everyone that can be considered "CIE" works to address these global crises of social justice from the macro to the micro, crises which are epistemologically often reinforced by a "common sense" (to echo your editorial) positivism that is taken for granted. Confronting what is "in the room" in CIE requires both our active engagement, as well as our simultaneous vigilance and self-subversion (Hale, 2014). The articles in the special issue bring this nuance of the challenges of doing CIE work to life.

\section{References}

Hale, S. (2014). A Propensity for Self-Subversion and a Taste for Liberation: An Afterword. Journal of Middle East Women's Studies, 10(1), 149-163. doi:10.2979/ jmiddeastwomstud.10.1.149.

Holliday, A. (2013). The politics of ethics in diverse cultural settings: colonising the centre stage. Compare: A Journal of Comparative and International Education, 43(4), 537-554. doi:10.108o/o3057925.2013.797775.

Rohrer, J. (2018). 'It's in the room': reinvigorating feminist pedagogy, contesting neoliberalism, and trumping post-truth populism. Teaching in Higher Education, 23(5), $576-592$. 